\title{
Echocardiographic left ventricular hypertrophy and geometry in Chinese chronic hemodialysis patients: the prevalence and determinants
}

Xinju Zhao ${ }^{1 \dagger}$, Li Zhư ${ }^{1 \dagger}$, Wenying Jin², Bing Yang ${ }^{1}$, Yan Wang ${ }^{1}$, Mengfan Ni, Yuchao Zhao ${ }^{1}$, Liangying Gan ${ }^{\text {* }}$ and Li Zuo'

\begin{abstract}
Background: To investigate the prevalence of left ventricular hypertrophy (LVH) and explore left ventricular geometry in maintenance hemodialysis (MHD) patients, and to explore the risk factors of LVH which is an important predictor of cardiovascular events.

Methods: The subjects were patients who are on MHD for more than 3 months in Peking University People's Hospital from March 2015 to February 2017. Demographic and clinical data were retrospectively collected. Left ventricular mass was measured by echocardiography. LVH is defined by Left ventricular mass index (LVMI) $>115 \mathrm{~g} / \mathrm{m}^{2}$ for men and $>95 \mathrm{~g} / \mathrm{m}^{2}$ in women. LVMI and relative wall thickness were used to determine left ventricular geometry. Logistic regression was used to analyze the risk factors of $\mathrm{LVH}$.

Results: Altogether, 131 patients including 77 males were enrolled. The median age was $60(47,69)$ years, with a median dialysis vintage of $48(18,104)$ months. There were 80 patients with $L V H$, the prevalence rate was $61.1 \%$, and $66.3 \%$ of them were moderate to severe LVH. We found that (1) most of the patients were concentric hypertrophy; (2) one-third of the patients were concentric remodeling; (3) only 4 cases with normal geometry. The pre-dialysis serum sodium level and time average pre-dialysis systolic blood pressure (SBP) were independent risk factors of LVH.
\end{abstract}

Conclusion: LVH is prevalent in MHD patients. Concentric hypertrophy and concentric remodeling are the most common geometric patterns. Attention should be paid to long-term pre-dialysis SBP management and pre-dialysis sodium control as they might be potentially modifiable risk factors for LVH.

Keywords: Maintenance hemodialysis, Left ventricular hypertrophy, Left ventricular mass index, Geometry, Risk factors

\section{*Correspondence: ganliangying@yahoo.com}

${ }^{\dagger}$ Xinju Zhao and Li Zhu have contributed equally to this work.

1 Department of Nephrology, Hemodialysis Center in Outpatient Building,

Peking University People's Hospital, 11 Xizhimennan Street, Xicheng

District, Beijing 100044, China

Full list of author information is available at the end of the article

\section{Background}

Cardiovascular disease (CVD) is the main complication and primary cause of death in patients with end stage kidney disease (ESKD), accounting for about $50 \%$ of the total death $[1,2]$. Left ventricular hypertrophy (LVH) plays a key role in the chain of cardiovascular events, which is closely related to the increase of cardiovascular 
events such as arrhythmia, atherosclerosis, stroke, and heart failure [3-5].

$\mathrm{LVH}$ is the most common cardiovascular abnormality in patients with chronic kidney disease (CKD) [6]. In non-dialysis dependent CKD patients, the prevalence of $\mathrm{LVH}$ is around 47\%; while in ESKD patients, the prevalence rate of LVH can be as high as $75-89 \%$. It is also reported that the risk of LVH increases with dialysis vintage and patients with LVH tend to progress.

LVH is often associated with a high risk of sudden cardiac death and is a predictor of cardiovascular death. The occurrence and continuous progression of LVH are associated with adverse cardiovascular prognosis and survival prognosis. However, the etiology of LVH in dialysis patients has not been fully clarified. The possible causes include anemia, hyperparathyroidism, toxin accumulation, malnutrition, etc., and volume overload and hypertension are still considered as important causes of $\mathrm{LVH}$ progression.

Diagnostic criteria for $\mathrm{LVH}$ had been updated. The prevalence of LVH in maintenance hemodialysis (MHD) patients under the relatively new diagnostic criteria is of great interest and value. The related research, especially for left ventricular geometry is few for Chinese MHD patients. Moreover, the risk factors deserve to be studied.

The purpose of this study was to explore the prevalence of LVH in Chinese MHD patients and the left ventricular geometry distribution determined by echocardiography, and to explore the risk factors of LVH to guide clinical treatment, so as to reduce the prevalence of $\mathrm{LVH}$, and reduce the risk of cardiovascular events and cardiovascular death.

\section{Methods}

\section{Study design and participants}

This study was a single center, retrospective cohort study. Eligible MHD patients in Peking University People's Hospital from March 2015 to February 2017 were enrolled. The inclusion criteria were: (1) who received MHD for more than 3 months; (2) who had echocardiography record in this period. The exclusion criteria were: (1) who had any active infections (bacterial and viral infections); (2) who had myocardial infarction, acute heart failure or stroke event occurred within 1 months of the echocardiography test; (3) History of malignant tumors, except for the following cases: tumors identified as cured or relieved for more than 5 years, cutaneous basal cells or squamous cell carcinoma or carcinoma in situ has been radically resected.

This study was conducted in accordance with the Declaration of Helsinki (as revised in 2013). The study was approved by the Ethics Committee of Peking University People's Hospital (ethical approval number:
2019PHB203-01). As this study was a retrospective observational cohort study without any intervention, informed consent was exempted by the Ethics Committee.

\section{Demographic and clinical data collection}

Demographic characteristics including age, gender, body mass index (BMI), dialysis vintage, assigned primary ESKD causes, dry weight, laboratory values including hemoglobulin, pre-dialysis biochemistry (serum creatinine, blood nitrogen, urine acid, calcium, phosphorus, potassium, sodium, chloride, $\mathrm{CO}_{2}$ binding capacity, glucose, total protein, albumin, total cholesterol, triglyceride, parathyroid hormone), Kt/v, nitrogen reduction rate (URR), and clinical data, such as average intradialytic weight loss (IDWL) of 3 consecutive sessions, monthly average of pre-dialysis and post-dialysis systolic and diastolic blood pressure (SBP and DBP) were retrospectively collected.

\section{Echocardiographic examination}

Transthoracic echocardiographic examinations were performed for all subjects (GE Vivid 7 or Vivid E9, GE Vingmed, Horten, Norway; ALOKA Prosound F75, Tokyo, Japan) with a 3-6 MHz phased array transducer. Standard two-dimensional echocardiography with Doppler examination was performed and measurements were obtained according to the guidelines of American Society of Echocardiography [7]. Left ventricular mass was measured by echocardiography and left ventricular mass index (LVMI) was calculated [8]. LVH is defined by LVMI $>115 \mathrm{~g} / \mathrm{m}^{2}$ for men and $>95 \mathrm{~g} / \mathrm{m}^{2}$ in women [9]. According to LVMI, LVH was further divided into mild, moderate, and severe category (Table 1) [9]. LVMI and relative wall thickness (RWT) were used to group the left ventricular geometry [9]. RWT is calculated by the formula $(2 \times$ posterior wall thickness)/(LV internal diameter at end-diastole) [10] and permits categorization of an increase in LV mass as either concentric (RWT >0.42) or eccentric (RWT $\leq 0.42)$ hypertrophy and allows the identification of concentric remodeling (normal LV mass with increased RWT, Table 2) [9].

Table 1 The LVH severity category

\begin{tabular}{lll}
\hline & $\begin{array}{l}\text { Female } \\
\text { LVMI }\left(\mathbf{g} / \mathbf{m}^{\mathbf{2}}\right)\end{array}$ & $\begin{array}{l}\text { Male } \\
\text { LVMI }\left(\mathbf{g} / \mathbf{m}^{\mathbf{2}}\right)\end{array}$ \\
\hline Normal & $43-95$ & $49-115$ \\
Mild & $96-108$ & $116-13,127$ \\
Moderate & $109-121$ & $132-148$ \\
Severe & $\geq 122$ & $\geq 149$ \\
\hline
\end{tabular}


Table 2 Left ventricular geometry classification

\begin{tabular}{lll}
\hline LV geometry & LVMI $\left(\mathbf{g} / \mathbf{m}^{\mathbf{2}}\right)$ & RWT \\
\hline Normal & $M \leq 115 ; F \leq 95$ & $\leq 0.42$ \\
Concentric remodeling & $M \leq 115 ; F \leq 95$ & $>0.42$ \\
Concentric hypertrophy & $M>115 ; F>95$ & $>0.42$ \\
Eccentric hypertrophy & $M>115 ; F>95$ & $\leq 0.42$
\end{tabular}

$M$ Male, $F$ Female

\section{Statistical analysis}

The continuous variables of normal distribution were expressed as mean \pm standard deviation, and the comparison of mean between groups was conducted by independent sample $t$ test. The continuous variables of non-normal distribution were expressed by median (25th, 75th). Wilcoxon rank sum test was used for comparisons. Categorical variables were expressed as rates or percentages, and comparisons between groups were performed by chi square test. Stepwise multivariate unconditional logistic regression analysis $(P<0.05)$ was conducted to determine the independent risk factors of LVH from all clinically relevant variables. We stratified continuous variables considered as risk factors into categorical variables to investigate the differences in $\mathrm{LVH}$ risk among subgroups of each variable. The patients were stratified into two groups according to the mean value of serum sodium level before dialysis in our study $(<138 \mathrm{mmol} / \mathrm{L}$ and $\geq 138 \mathrm{mmol} / \mathrm{L})$. The patients also stratified according to their average pre-dialysis systolic blood pressure. $P<0.05$ was statistically significant. The statistics were completed by SAS software (version 9.4, SAS Institute, Cary, NC, USA).

\section{Results}

A total of 131 patients with 77 males and 54 females were enrolled. The median age was $60(47,69)$ years old, with a median dialysis vintage of $48(18,104)$ months (Table 3). There were 80 patients with LVH. The prevalence of $\mathrm{LVH}$ in this single center was $61.1 \%$. Among LVH patients, $66.3 \%$ of them were moderate or severe LVH (Fig. 1). Compared with patients without $\mathrm{LVH}$, patients with LVH had lower level of total protein $(71.90 \pm 5.32$ vs. $69.90 \pm 4.05, P=0.019)$, higher potassium level ( $4.71 \pm 0.73$ vs. $5.05 \pm 0.74, P=0.014)$, higher Pre-dialysis SBP and Post-dialysis SBP. The median dialysis vintage was 56 months in the LVH group and 40 months in the non-LVH group, but not statistically significant $(P=0.196)$.

The left ventricular geometry showed that there were 47 cases with concentric remodeling, 71 cases with concentric hypertrophy, 9 cases with eccentric hypertrophy, and only 4 cases with normal left ventricular geometry (Fig. 2).

For echocardiography indies, compared with patients in non LVH group, LVEF was lower, while main pulmonary artery diameter, anteroposterior diameter of left atrium, interventricular septum at end-diastole, left ventricular internal diameter at end-diastole, left ventricular internal diameter at end-systole, and inferolateral wall thickness were greater in LVH group.

Stepwise logistic regression analysis showed that predialysis serum sodium level and pre-dialysis systolic blood pressure were independent risk factors of $\mathrm{LVH}$, and OR values were 1.136 (95\% CI 1.005-1.284) and 1.047 (95\% CI 1.017-1.079), respectively. Further stratified analysis of pre-dialysis serum sodium and blood pressure showed that patients with $\mathrm{Na} \geq 138 \mathrm{mmol} / \mathrm{L}$ or systolic blood pressure higher than $150 \mathrm{mmHg}$ had an increased risk of LVH (Table 4).

\section{Discussion}

In the current study, we found that the prevalence of $\mathrm{LVH}$ is high in MHD patients, and most of them are concentric hypertrophy, which is consistent with previous studies. Patients with complete normal cardiac geometry is rare. Even in MHD patients without $\mathrm{LVH}$, concentric remodeling is also common. However, the prevalence of eccentric hypertrophy seems to be a little lower than reported, which might be influenced by the different study population.

In literature, $\mathrm{LVH}$ is present in $68-89 \%$ of incident HD patients [11-14]. Chronic volume overload, hypertension, high output of AV fistulae, anemia, and uremic toxin accumulation all contribute to LVH in MHD [15]. Excessive sodium can induce water retention and hence excessive volume. Volume overload has been recognized as one of the main etiologies of hypertension in HD patients [16]. Reversely, accurate assessment and management of volume status was shown to be associated with reduced volume overload and LVH improvement [17]. The correlation between dialysis vintage and LVH is supported by evidence [18]. However, the difference for dialysis vintage between the LVH group and non-LVH group did not reach the statistical significance at $P<0.05$ in our study, which might be limited by the relatively small sample size.

Although regression can be observed in a minority of patients, more often, LVH progresses. Zoccali et al. followed up $161 \mathrm{MHD}$ patients without chronic congestive heart failure (LVEF > 35\%) for 18 months. The researchers found that LVMI increased by $6.7 \%$ at the end of followup [19]. Levin et al. conducted a prospective multicenter cohort study in Canadian patients with a total of 246 
Table 3 Baseline characteristics of MHD patients with and without LVH

\begin{tabular}{|c|c|c|c|c|}
\hline Variables & All $(n=131)$ & $\operatorname{LVH}(n=80)$ & Non-LVH $(n=51)$ & $P$ value \\
\hline \multicolumn{5}{|l|}{ Demographics } \\
\hline Age (years) & $60(47,69)$ & $59.5(49.5,70.5)$ & $61(46,68)$ & 0.479 \\
\hline Males (\%) & & 53.75 & 66.67 & 0.151 \\
\hline Vintage (months) & $48(18,104)$ & $56(24,114)$ & $40(17,98)$ & 0.196 \\
\hline BMI $\left(\mathrm{kg} / \mathrm{m}^{2}\right)$ & $22.6(20.3,25.3)$ & $22.8(20.1,25.4)$ & $22.1(20.5,24.9)$ & 0.489 \\
\hline ESRD causes (\%) & & & & - \\
\hline Glomerulonephritis & 49.6 & 53.8 & 43.1 & \\
\hline Diabetic nephropathy & 16.8 & 15.0 & 19.6 & \\
\hline Hypertensive nephropathy & 11.5 & 6.3 & 19.6 & \\
\hline Others & 22.1 & 25.0 & 17.7 & \\
\hline \multicolumn{5}{|l|}{ Laboratory tests } \\
\hline $\mathrm{Hgb}(\mathrm{g} / \mathrm{l})$ & $114(108,121)$ & $115.5(108,121)$ & $113(107,120)$ & 0.283 \\
\hline Alb (g/l) & $39.7(37.8,41.8)$ & $39.2 \pm 3.2$ & $39.7 \pm 3.8$ & 0.112 \\
\hline BUN (mmol/l) & $28.2(23.5,32.4)$ & $28.8(23.5,33.5)$ & $27.6(22.9,29.9)$ & 0.132 \\
\hline Creatine ( $\mu \mathrm{mol} / \mathrm{l})$ & $1004(852,1191)$ & $1011(880,1191)$ & $983(837,1188)$ & 0.513 \\
\hline UA $(\mu \mathrm{mol} / \mathrm{I})$ & $449.6 \pm 94.5$ & $450 \pm 101.8$ & $448 \pm 82.6$ & 0.884 \\
\hline adjusted Ca (mmol/l) & $9.4 \pm 0.7$ & $9.4 \pm 0.7$ & $9.4 \pm 0.7$ & 0.716 \\
\hline $\mathrm{P}(\mathrm{mmol} / \mathrm{l})$ & $1.62 \pm 0.54$ & $1.62 \pm 0.56$ & $1.64 \pm 0.51$ & 0.817 \\
\hline PTH ( $\mu \mathrm{g} / \mathrm{ml})$ & $173.0(96.4,337.6)$ & $186.5(107.4,361.7)$ & $163.7(58.1,300.7)$ & 0.186 \\
\hline LDL (mmol/l) & $2.28 \pm 0.81$ & $2.21 \pm 0.83$ & $2.37 \pm 0.76$ & 0.271 \\
\hline $\mathrm{HDL}(\mathrm{mmol} / \mathrm{l})$ & $0.98(0.82,1.25)$ & $0.98(0.79,1.25)$ & $1.00(0.84,1.24)$ & 0.500 \\
\hline Total cholesterol (mmol/l) & $4.11(3.51,4.81)$ & $4.27(3.72,4.84)$ & $4.00(3.46,4.74)$ & 0.402 \\
\hline Triglyceride $(\mathrm{mmol} / \mathrm{l})$ & $1.94(1.29,2.75)$ & $1.94(1.22,2.62)$ & $1.90(1.31,3.16)$ & 0.500 \\
\hline Total Protein (g/l) & $70.68 \pm 4.67$ & $69.9 \pm 4.05$ & $71.9 \pm 5.32$ & 0.019 \\
\hline Glucose (mmol/l) & $6.71(5.41,9.18)$ & $6.77(5.72,9.02)$ & $6.65(5.30,9.68)$ & 0.992 \\
\hline Potassium (mmol/l) & $4.92 \pm 0.75$ & $5.05 \pm 0.74$ & $4.71 \pm 0.73$ & 0.014 \\
\hline $\mathrm{Na}(\mathrm{mmol} / \mathrm{l})$ & $138.0 \pm 3.4$ & $138.2 \pm 3.3$ & $137.6 \pm 3.6$ & 0.354 \\
\hline $\mathrm{CO}_{2} \mathrm{CP}(\mathrm{mmol} / \mathrm{l})$ & $23.8 \pm 3.0$ & $23.5 \pm 2.9$ & $24.4 \pm 3.2$ & 0.109 \\
\hline \multicolumn{5}{|l|}{ Dialysis related indices } \\
\hline $\mathrm{spKt} / \mathrm{N}$ & $1.49 \pm 0.26$ & $1.47 \pm 0.27$ & $1.51 \pm 0.24$ & 0.378 \\
\hline URR (\%) & $70.46 \pm 7.26$ & $70.03 \pm 7.04$ & $71.13 \pm 7.63$ & 0.411 \\
\hline Fistula use (\%) & 84.7 & 85.0 & 84.3 & 1.000 \\
\hline Intradialytic weight loss (kg) & $2.7(2.3,3.2)$ & $2.7(2.3,3.3)$ & $2.5(2.0,3.0)$ & 0.145 \\
\hline \multicolumn{5}{|c|}{ Clinical and echocardiography indices (\%) } \\
\hline Pre-dialysis SBP (mmHg) & $151 \pm 16$ & $154 \pm 14$ & $146 \pm 17$ & 0.004 \\
\hline Pre-dialysis DBP (mmHg) & $76 \pm 11$ & $77 \pm 12$ & $75 \pm 10$ & 0.367 \\
\hline Post-dialysis SBP (mmHg) & $145 \pm 16$ & $148 \pm 15$ & $141 \pm 18$ & 0.008 \\
\hline Post-dialysis DBP (mmHg) & $79 \pm 11$ & $80 \pm 12$ & $79 \pm 11$ & 0.702 \\
\hline $\operatorname{LVM}(g)$ & $197.5(161.7,262.0)$ & $243.5(199.1,280.8)$ & $149.0(123.6,181.9)$ & $<0.001$ \\
\hline LVMI $\left(g / m^{2}\right)$ & $115.0(95.9,144.7)$ & $133.1(120.9,161.1)$ & $87.7(77.2,97.7)$ & $<0.001$ \\
\hline $\operatorname{LVEF}(\%)$ & $65.3(59.3,71.1)$ & $63.3(54.8,69.2)$ & $68.6(63.1,72.0)$ & 0.003 \\
\hline MPA (cm) & $2.3(2.1,2.5)$ & $2.3(2.2,2.7)$ & $2.2(2.1,2.4)$ & 0.013 \\
\hline LAD (cm) & $3.8(3.4,4.1)$ & $3.9(3.5,4.4)$ & $3.9(3.3,4.0)$ & 0.005 \\
\hline IVSd (cm) & $1.0(0.9,1.1)$ & $1.1(1.0,1.2)$ & $0.9(0.8,1.0)$ & $<0.001$ \\
\hline LVIDd (cm) & $5.0(4.6,5.4)$ & $5.1(4.9,5.7)$ & $4.5(4.3,5.0)$ & $<0.001$ \\
\hline LVIDs (cm) & $3.2(2.8,3.6)$ & $3.4(3.1,3.9)$ & $2.9(2.7,3.2)$ & $<0.001$ \\
\hline PWT (cm) & $0.97(0.88,1.10)$ & $1.00(0.90,1.10)$ & $0.90(0.80,1.00)$ & $<0.001$ \\
\hline
\end{tabular}

$B M I$ body mass index, $H g b$ haemoglobin, $A / b$ albumin, spKt/V single-pooled $K t / V$, stdKt/V standardized Kt/V, LVM left ventricular mass, LVMI left ventricular mass index, LVEF left ventricular ejection fraction, MPA main pulmonary artery diameter, $L A D$ anteroposterior diameter of left atrium, IVSd interventricular septum at end-diastole, LVIDd left ventricular internal diameter at end-diastole, LVIDs left ventricular internal diameter at end-systole, PWT inferolateral wall thickness 


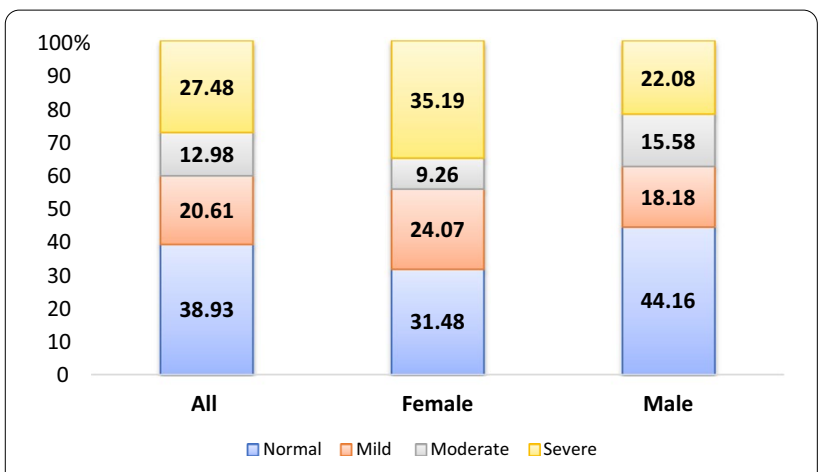

Fig. 1 The distribution (\%) of left ventricular hypertrophy severity in MHD patients

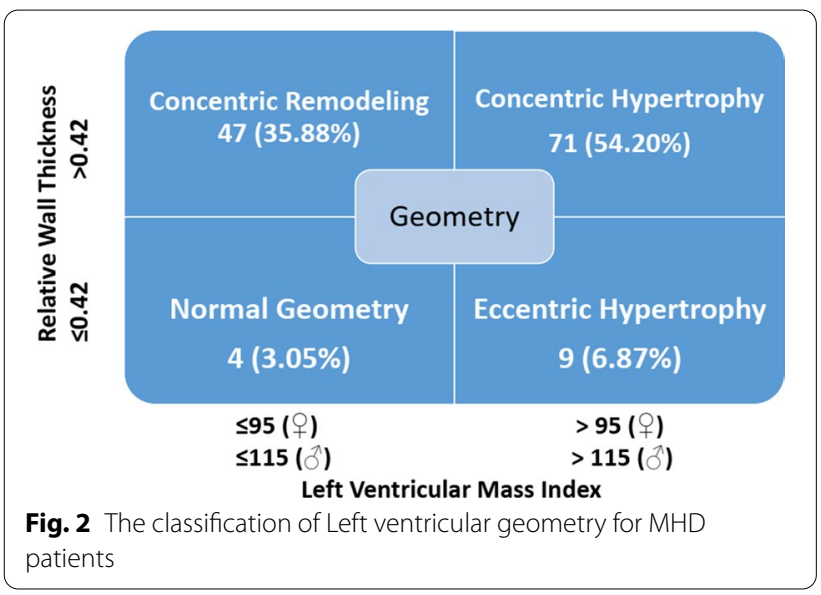

Table 4 Stepwise multivariate logistic regression analysis and stratified analysis of risk factors

\begin{tabular}{llll}
\hline & OR value & $\mathbf{9 5 \% C l}$ & $\boldsymbol{P}$ value \\
\hline Pre-dialysis sodium(mmol/L) & 1.136 & $1.005-1.284$ & 0.041 \\
$<138$ & ref & ref & ref \\
$\geq 138$ & 1.146 & $1.012-1.296$ & 0.031 \\
Pre-dialysis SBP $(\mathrm{mmHg})$ & 1.047 & $1.017-1.079$ & 0.002 \\
$\leq 130$ & ref & ref & ref \\
$131-139$ & 1.949 & $0.300-12.651$ & 0.117 \\
$140-149$ & 7.670 & $1.500-39.210$ & 0.243 \\
$150-159$ & 12.891 & $2.611-63.638$ & 0.010 \\
$\geq 160$ & 12.412 & $2.461-62.605$ & 0.018 \\
\hline
\end{tabular}

patients included. In their study, one quarter of patients were found to have increased LVH after 1 year of follow-up [20]. Foley et al. followed up 596 newly dialyzed patients (dialysis vintage $<18$ months) without obvious heart disease and cardiac enlargement. Their study found that no matter what treatment was randomly given, the average LVMI of patients showed a trend of progression. LVMI was $114 \mathrm{~g} / \mathrm{m}^{2}$ at baseline, $121 \mathrm{~g} / \mathrm{m}^{2}$ at week 24 , $123 \mathrm{~g} / \mathrm{m}^{2}$ at week 48 , and $128 \mathrm{~g} / \mathrm{m}^{2}$ at week $96(P<0.001)$ [21].

LVH can be served as a risk factor for cardiac and allcause mortality [22]. Stack et al. found that in the incident dialysis patients, the survival rate of patients with $\mathrm{LVH}$ at 6 months, 12 months and 24 months was worse than that of patients without $\mathrm{LVH}$, and the relative risk of death was $1.61,1.36$ and 1.29 respectively [23]. LVH also significantly increases the risk of heart failure [24]. The risk of heart failure in patients with cardiotropic $\mathrm{LVH}$ and left ventricular dilatation was 3.7 times and 4.7 times higher than those with normal measurement [25]. Researchers found that 10\% decrease of LVM was independently associated with $22 \%$ and $28 \%$ decreased risk of all-cause and cardiovascular mortality [26]. The above publications reveal that $\mathrm{LVH}$ is associated with worse clinical outcomes and might be a modifiable risk factor for mortality.

How to delay or reverse LVH is the key and difficult point in the treatment of maintenance hemodialysis patients. However, in addition to intensive dialysis, treatment interventions are very limited [3]. It has been a long time since scholars recognized hypertension as a risk factor for LVH in hypertensive and CKD populations [2730]. However, for MHD patients to what extent the blood pressure is associated with LVH and which blood pressure level is associated an increased risk is not well studied [31]. Our findings suggested that the time average pre-dialysis SBP was independently associated with LVH. As far as we know, this is the first manuscript introducing time average blood pressure concept. $\mathrm{LVH}$ is a time dependent cumulative effect of volume and post cardiac overload. Not surprisingly, some research with random blood pressure levels showed a negative result. Moreover, our stratified analysis showed that only the time average pre-dialysis SBP $>150 \mathrm{mmHg}$ was associated with an increased risk of $\mathrm{LVH}$. This result suggested that the target of pre-dialysis SBP for MHD patients should not exceed $150 \mathrm{mmHg}$ in terms of reign LVH. Nowadays, some research and guidelines recommend to measure blood pressure on inter-dialytic days, based on the evidences that inter-dialytic blood pressure measurements were shown to be better associated with 44-h ambulatory blood pressure and mortality in HD patients. Whether the inter-dialytic blood pressure will be a risk factor for $\mathrm{LVH}$ and surpass pre-dialysis blood pressure is warrant further studies.

In our study, we also found that the pre-dialysis serum sodium level is an independent risk factor of LVH. A large amount of empirical evidence has linked sodium excess to increased incidence and mortality of cardiovascular 
disease in HD patients. Sodium retention is common in patients undergoing dialysis. LVH could be mediated by sodium retention through hypertension, increased intravascular volume, increased afterload and cardiac traction. We found the risk of LVH was increased in patients with serum sodium $\geq 138 \mathrm{mmol} / \mathrm{L}$ in our study, which is our median value of sodium level and also a well-used cut off value to assess prognosis [32-34]. Our finding is consistent with former study [34]. Moreover, scholars suggest that adjusting dialysate sodium concentration might be a simple method to ameliorate sodium retention for HD patients. It is expected to improve sodium regulation in HD patients by lowering dialysate sodium, so as to reduce chronic fluid and sodium overload. The value $138 \mathrm{mmol} / \mathrm{L}$ is the routine prescription sodium concentration in dialysate in our hemodialysis center. For dialysis patients, the optimal serum and dialysate sodium level is always on a debate focus [35]. Our finding suggests that the serum sodium level should not exceed $138 \mathrm{mmol} / \mathrm{L}$ in MHD patients.

In other studies, researchers found that intradialytic weight loss or inter-dialytic weight gain was associated with LVH [36]. However, in our stepwise regression analysis, we were not able to identify it as a risk factor. We use the average value of 3 consecutive HD sessions which may not be so representative of a long-time volume load. Whether monthly, quarterly or even yearly average IDWL will be a risk factor of LVH is worthy further research. Some studies suggest that cardiac valvular calcification may be one of the risk factors for left ventricular hypertrophy, while our results have no statistical difference [37]. It is worthy further study.

However, our study has several limitations. Firstly, this is a single center, retrospective, observational study which might has inherent shortcomings such as selection bias and confounding factors. Secondly, the small sample size in our study makes it impossible for us to perform more detailed subgroup analysis. To solve this problem, we have used a relatively more flexible inclusion criteria of enrolling patients being on HD treatment for more than 3 months instead of 6 months or longer. This criterion enabled us to include as many eligible participates as possible, and guaranteed that they are all MHD patients as well. Usually, being on HD treatment more than 3 months is recognized as MHD patients, and most studies in HD population enrolled participants on HD more than 3 months [38-40]. Furthermore, some research suggested that 3 months might be long enough to make a difference on the progression of LVH in HD population [41]. Therefore, we believe that this design will not affect our main findings though further large scale and welldesigned prospective study is needed. Thirdly, comorbidity and medicine information were not collected in this study which might cause bias. Even though, the results of this study have value for us to understand the LVH epidemiology and to explore potential modifiable risk factors of LVH, and hence might be able to reduce the LVH risk and improve patients' survival.

\section{Conclusion}

In conclusion, the prevalence of LVH in MHD patients in China is high, and normal geometry is rare. Routine echocardiography examination to detect $\mathrm{LVH}$ and left ventricular geometry in MHD patients is highly recommended. We revealed that pre-dialysis SBP and pre-dialysis sodium might be potential modifiable risk factors for LVH. We suggest that the pre-dialysis SBP should not exceed $150 \mathrm{mmHg}$ and pre-dialysis serum sodium should be less than $138 \mathrm{mmol} / \mathrm{L}$ in MHD patients for cardiac protection, which warrants further study.

\section{Abbreviations \\ BMI: Body mass index; CKD: Chronic kidney disease; CVD: Cardiovascular disease; DBP: Diastolic blood pressure; ESKD: End stage kidney disease; IDWL: Intradialytic weight loss; LVH: Left ventricular hypertrophy; LVMI: Left ventricu- lar mass index; MHD: Maintenance hemodialysis; RWT: Relative wall thickness; SBP: Systolic blood pressure; URR: Nitrogen reduction rate.}

\section{Acknowledgements}

The authors express their gratitude to all patients in our study.

\section{Authors' contributions}

$X Z$ : conception and design or analysis and interpretation of data, drafting of the manuscript or revising it critically for important intellectual content, LZ: conception and design or analysis and interpretation of data, drafting of the manuscript or revising it critically for important intellectual content, WJ: collect data, BY: collect data, YW: collect data, MN: collect data, YZ: collect data, LG: conception and design or analysis and interpretation of data, final approval of the manuscript submitted, LZ: conception and design the study and revising the manuscript. All authors read and approved the final manuscript.

\section{Funding}

Grants from Capital Clinical Characteristics Application Program (No Z131107002213122). Project (RDY2021-29) Supported by Peking University People's Hospital Research And Development Funds.

\section{Availability of data and material}

The datasets used and/or analyzed during the current study are available from the corresponding author on reasonable request.

\section{Declarations}

\section{Ethics approval and consent to participate}

This study was conducted in accordance with the Declaration of Helsinki (as revised in 2013). The study was approved by the Ethics Committee of Peking University People's Hospital (ethical approval number: 2019PHB203-01). As this study was a retrospective observational cohort study without any intervention, informed consent was exempted by the Ethics Committee of Peking University People's Hospital (ethical approval number: 2019PHB203-01).

\section{Consent for publication}

Not applicable.

Competing interests

The authors declare that they have no conflict of interest. 


\section{Author details}

${ }^{1}$ Department of Nephrology, Hemodialysis Center in Outpatient Building, Peking University People's Hospital, 11 Xizhimennan Street, Xicheng District, Beijing 100044, China. ${ }^{2}$ Department of Cardiology, Peking University People's Hospital, Beijing, China.

Received: 5 October 2021 Accepted: 10 February 2022 Published online: 16 February 2022

\section{References}

1. Liu M, Li XC, Lu L, Cao Y, Sun RR, Chen S, Zhang PY. Cardiovascular disease and its relationship with chronic kidney disease. Eur Rev Med Pharmacol Sci. 2014;18(19):2918-26.

2. United States Renal Data System. 2020 USRDS annual data report: epidemiology of kidney disease in the United States. Bethesda: National Institutes of Health, National Institute of Diabetes and Digestive and Kidney Diseases; 2020.

3. McCullough PA, Chan CT, Weinhandl ED, Burkart JM, Bakris GL. Intensive hemodialysis, left ventricular hypertrophy, and cardiovascular disease. Am J Kidney Dis. 2016;68(5S1):S5-14.

4. Bombelli M, Facchetti R, Carugo S, Madotto F, Arenare F, Quarti-Trevano F, Capra A, Giannattasio C, Dell'Oro R, Grassi G, Sega R, Mancia G. Left ventricular hypertrophy increases cardiovascular risk independently of in-office and out-of-office blood pressure values. J Hypertens. 2009;27(12):2458-64.

5. Verdecchia P, Angeli F, Achilli P, Castellani C, Broccatelli A, Gattobigio R, Cavallini C. Echocardiographic left ventricular hypertrophy in hypertension: Marker for future events or mediator of events? Curr Opin Cardiol. 2007;22(4):329-34.

6. Di Lullo L, Gorini A, Russo D, Santoboni A, Ronco C. Left ventricular hypertrophy in chronic kidney disease patients: from pathophysiology to treatment. Cardiorenal Med. 2015;5(4):254-66.

7. Mitchell C, Rahko PS, Blauwet LA, Canaday B, Finstuen JA, Foster MC, Horton K, Ogunyankin KO, Palma RA, Velazquez EJ. Guidelines for performing a comprehensive transthoracic echocardiographic examination in adults: recommendations from the American society of echocardiography. J Am Soc Echocardiogr. 2019;32(1):1-64. https://doi.org/10.1016/j.echo.2018. 06.004 .

8. Devereux RB, Alonso DR, Lutas EM, Gottlieb GJ, Campo E, Sachs I, Reichek N. Echocardiographic assessment of left ventricular hypertrophy: comparison to necropsy findings. Am J Cardiol. 1986;57(6):450-8. https://doi. org/10.1016/0002-9149(86)90771-X.

9. Lang RM, Bierig M, Devereux RB, Flachskampf FA, Foster E, Pellikka PA, Picard MH, Roman MJ, Seward J, Shanewise J, Solomon S, Spencer KT, StJohnSutton M, Stewart W, American Society of Echocardiography's Nomenclature and Standards Committee, Task Force on Chamber Quantification, American College of Cardiology Echocardiography Committee, American Heart Association, European Association of Echocardiography, European Society of Cardiology. Recommendations for chamber quantification. Eur J Echocardiogr. 2006;7(2):79-108. https://doi.org/10.1016/j. euje.2005.12.014.

10. Sierra C, de la Sierra A, Paré JC, Gómez-Angelats E, Coca A. Correlation between silent cerebral white matter lesions and left ventricular mass and geometry in essential hypertension. Am J Hypertens. 2002;15(6):50712. https://doi.org/10.1016/s0895-7061(02)02277-X.

11. Qin Z, Yang Q, Yang M, Han M, Xiong Y, Liao R, Su B. Serum leptin concentration can predict cardiovascular outcomes and all-cause death in maintenance hemodialysis patients. Clin Chim Acta. 2021;520:87-94.

12. Levin A, Singer J, Thompson CR, Ross $H$, Lewis M. Prevalent left ventricular hypertrophy in the predialysis population: identifying opportunities for intervention. Am J Kidney Dis. 1996;27(3):347-54.

13. Eckardt KU, Scherhag A, Macdougall IC, Tsakiris D, Clyne N, Locatelli F, Zaug MF, Burger HU, Drueke TB. Left ventricular geometry predicts cardiovascular outcomes associated with anemia correction in CKD. J Am Soc Nephrol. 2009;20(12):2651-60.

14. Parfrey PS, Foley RN. The clinical epidemiology of cardiac disease in chronic renal failure. J Am Soc Nephrol. 1999;10(7):1606-15.
15. Ahmadmehrabi S, Tang WHW. Hemodialysis-induced cardiovascular disease. Semin Dial. 2018;31(3):258-67.

16. Georgianos Pl, Agarwal R. Blood pressure control in conventional hemodialysis. Semin Dial. 2018;31(6):557-62.

17. Chang ST, Chen CC, Chen CL, et al. Changes of the cardiac architectures and functions for chronic hemodialysis patients with dry weight determined by echocardiography. Blood Purif. 2004;22(4):351-9.

18. Liu C, Feng YP, Yan ZN, Fan L, Rui YF, Cui L. Value of quantitative analysis of left ventricular systolic function in patients on maintenance hemodialysis based on myocardial work technique. BMC Cardiovasc Disord. 2021;21(1):76.

19. Zoccali C, Benedetto FA, Mallamaci F, Tripepi G, Giacone G, Stancanelli B, Cataliotti A, Malatino LS. Left ventricular mass monitoring in the followup of dialysis patients: prognostic value of left ventricular hypertrophy progression. Kidney Int. 2004;65(4):1492-8.

20. Levin A, Thompson CR, Ethier J, Carlisle EJ, Tobe S, Mendelssohn D, Burgess $E$, Jindal $K$, Barrett B, Singer J, Djurdjev O. Left ventricular mass index increase in early renal disease: impact of decline in hemoglobin. Am J Kidney Dis. 1999;34(1):125-34.

21. Foley RN, Curtis BM, Randell EW, Parfrey PS. Left ventricular hypertrophy in new hemodialysis patients without symptomatic cardiac disease. Clin J Am Soc Nephrol. 2010;5(5):805-13.

22. Charytan D. Is left ventricular hypertrophy a modifiable risk factor in endstage renal disease. Curr Opin Nephrol Hypertens. 2014;23(6):578-85.

23. Stack AG, Saran R. Clinical correlates and mortality impact of left ventricular hypertrophy among new ESRD patients in the United States. Am J Kidney Dis. 2002;40(6):1202-10.

24. Lewis AA, Ayers CR, Selvin E, Neeland I, Ballantyne CM, Nambi V, Pandey A, Powell-Wiley TM, Drazner MH, Carnethon MR, Berry JD, Seliger SL, DeFilippi CR, de Lemos JA. Racial differences in malignant left ventricular hypertrophy and incidence of heart failure: a multicohort study. Circulation. 2020;141(12):957-67.

25. Foley RN, Parfrey PS, Harnett JD, Kent GM, Murray DC, Barre PE. The impact of anemia on cardiomyopathy, morbidity, and and mortality in end-stage renal disease. Am J Kidney Dis. 1996;28(1):53-61.

26. London GM, Pannier B, Guerin AP, Blacher J, Marchais SJ, Darne B, Metivier F, Adda H, Safar ME. Alterations of left ventricular hypertrophy in and survival of patients receiving hemodialysis: follow-up of an interventional study. J Am Soc Nephrol. 2001;12(12):2759-67.

27. Konings CJ, Kooman JP, Schonck M, Dammers R, Cheriex E, Palmans Meulemans AP, Hoeks AP, van Kreel B, Gladziwa U, van der Sande FM, Leunissen KM. Fluid status, blood pressure, and cardiovascular abnormalities in patients on peritoneal dialysis. Perit Dial Int. 2002;22(4):477-87.

28. Fagugli RM, Pasini P, Quintaliani G, Pasticci F, Ciao G, Cicconi B, Ricciardi D, Santirosi PV, Buoncristiani E, Timio F, Valente F, Buoncristiani U. Association between extracellular water, left ventricular mass and hypertension in haemodialysis patients. Nephrol Dial Transplant. 2003;18(11):2332-8.

29. Wang T, Li Y, Wu H, Chen H, Zhang Y, Zhou H, Li H. Optimal blood pressure for the minimum all-cause mortality in Chinese ESRD patients on maintenance hemodialysis. Biosci Rep. 2020;40(8):BSR20200858.

30. Ogawa T, Nitta K. Clinical impact of left ventricular diastolic dysfunction in chronic kidney disease. Contrib Nephrol. 2018;195:81-91.

31. Taddei S, Nami R, Bruno RM, Quatrini I, Nuti R. Hypertension, left ventricular hypertrophy and chronic kidney disease. Heart Fail Rev. 2011;16(6):615-20.

32. Oliva-Damaso N, Baamonde-Laborda E, Oliva-Damaso E, Payan J, Marañes A, Vega-Diaz N, Rodriguez-Perez JC. Fluctuation of pre-hemodialysis serum sodium. Clin Nephrol. 2018;90(6):396-403. https://doi.org/10.5414/ CN109355.

33. Rhee CM, Ravel VA, Ayus JC, Sim JJ, Streja E, Mehrotra R, Amin AN, Nguyen DV, Brunelli SM, Kovesdy CP, Kalantar-Zadeh K. Pre-dialysis serum sodium and mortality in a national incident hemodialysis cohort. Nephrol Dial Transplant. 2016;31(6):992-1001. https://doi.org/10.1093/ndt/gfv341.

34. Chen Z, Sun F, Shen Y, Ma L, Liu J, Zhou Y. Impact of dialysate sodium concentration lowering on home blood pressure variability in hemodialysis patients. Ther Apher Dial. 2019;23(2):153-9. https://doi.org/10.1111/17449987.12771.

35. Ramaswamy K, Brahmbhatt Y, Xia J, Song Y, Zhang J. Individualized dialysate sodium prescriptions using sodium gradients for high-risk hemodialysis patients lowered interdialytic weight gain and achieved target weights. Hemodial Int. 2020;24(3):406-13. 
36. Ozkahya M, Toz H, Qzerkan F, Duman S, Ok E, Basci A, Mees EJ. Impact of volume control on left ventricular hypertrophy in dialysis patients. $J$ Nephrol. 2002;15(6):655-60.

37. Li M, Ye ZC, Li CM, Zhao WB, Tang H, Liu X, Peng H, Lou TQ. The influence of cardiac valvular calcification on all-cause and cardiovascular mortality in maintenance hemodialysis patients. Int Urol Nephrol. 2020;52(5):943-51.

38. Iyasere OU, Brown EA, Johansson L, Huson L, Smee J, Maxwell AP, Farrington K, Davenport A. Quality of life and physical function in older patients on dialysis: a comparison of assisted peritoneal dialysis with hemodialysis. Clin J Am Soc Nephrol. 2016;1 (3):423-30.

39. Pu J, Jiang Z, Wu W, Li L, Zhang L, Li Y, Liu Q, Ou S. Efficacy and safety of intradialytic exercise in haemodialysis patients: a systematic review and meta-analysis. BMJ Open. 2019;9(1):e020633.

40. Barra ABL, Roque-da-Silva AP, Vasconcellos MS, Lugon JR, Strogoff-deMatos JP. Association between extracellular volume control and survival in patients on short daily haemodialysis. BMC Nephrol. 2020;21(1):153.

41. Ori Y, Korzets A, Katz M, Erman A, Weinstein T, Malachi T, Gafter U. The contribution of an arteriovenous access for hemodialysis to left ventricular hypertrophy. Am J Kidney Dis. 2002;40(4):745-52.

\section{Publisher's Note}

Springer Nature remains neutral with regard to jurisdictional claims in published maps and institutional affiliations.

- fast, convenient online submission

- thorough peer review by experienced researchers in your field

- rapid publication on acceptance

- support for research data, including large and complex data types

- gold Open Access which fosters wider collaboration and increased citations

- maximum visibility for your research: over $100 \mathrm{M}$ website views per year

At BMC, research is always in progress.

Learn more biomedcentral.com/submissions 